\title{
LA SOLICITUD DE SANTO TORIBIO POR EL PATRIMONIO RELIGIOSO DEL PERÚ
}

\author{
SANTO TORIBIO’S APLLICATION FOR PERUVIAN RELIGIOUS HERITAGE
}

José Antonio Benito Rodríguez ${ }^{1}$

\section{RESUMEN}

Cuando vino Juan Pablo II al Perú, su conferencia central a los obispos peruanos versó sobre cuatro facetas de santo Toribio: su vida de santidad, su compromiso en la formación integral de los nativos, su apuesta por la comunión e integración y su estrecha vinculación con el Papado. Las cuatro son como pilares de su vocación y misión de constructor de la Iglesia del Perú. Este santo padre de la Iglesia de América -en frase de su primer biógrafo León Pinelo- "no perdió su tiempo" y se puso manos a la obra construyendo la Iglesia, que él denominaba "la nueva cristiandad de las Indias". Trece sínodos diocesanos, tres concilios provinciales con sus instrumentos catequéticos como el Catecismo trilingüe (en castellano, quechua y aymara), las Visitas pastorales, impulsor de instituciones como el Seminario o el Convento de Santa Clara, organizaciones como nuevas cofradías, parroquias, poblados, durante 25 años, pusieron las bases del actual patrimonio religioso del Perú. Tal patrimonio queda patente en la cultura de santidad de sus contemporáneos como Rosa de Lima y Martín, a quienes confirmó, Juan Macías, Francisco Solano y numerosos beatos y siervos de Dios a quienes ayudó. Pero, además en la construcción de iglesias como la Catedral, conventos como Santa Clara, y las numerosas parroquias y capillas, cofradías y doctrinas, dispersas por todo su dilatado territorio arzobispal.

\section{Palabras clave}

Santo Toribio, patrimonio, arzobispado de Lima, santidad, construcción

\section{ABSTRACT}

When Juan Pablo II came to Peru, his central conference for the Peruvian bishops was about the four stages of St. Toribio: his life of holiness, his commitment in the complete education of natives, his commitment to integration and communion and his close relationship with the papacy. The fourth are like pillars of his mission and vocations of the Peruvian church builder. This holy father of the American Church, in words of his first biographer Leon Pinelo: "he didn't' waste his time" and he began working the Church, which he called "the new Christendom of the Indies". Thirteen diocesan synods, three provincial councils with his catechetical instruments such as the Trilingual Catechism (in Spanish, Quechua and Aymara) and the Pastoral visits. Instigator of institutions such as the Santa Clara Seminary or Convent, organizations as a new association, parishes and towns .During 25 years, they laid the basis of the current Peruvian religious heritage. This heritage is reflected in the culture of holiness of his contemporaries such as Rose of Lima and Martin who St. Toribio confirmed, Juan Macias, Francisco Solano and a lot of Blessed and servants of god who he also helped. But also St. Toribio helped in the building of churches like the Cathedral, Convents such as Santa Clara and the numerous parishes and chapels, fraternities and doctrines, dispersed throughout all his archbishop territory.

\section{Keywords}

St. Toribio, patrimony, Lima Archbishopric, holiness, building

\footnotetext{
Es diplomado en Educación por la Universidad de Salamanca, Doctor en Historia de América. Miembro Ordinario de la Asociación Española de Americanistas, de la sección de Historia del Instituto "Riva/Agüero" y de la Academia Peruana de Historia de la Iglesia. Profesor universitario. Ha publicado 25 libros de tema americanista y alrededor de 200 artículos. Conduce el programa de televisión "El Puente" en PAX TV y el de "Historias santas de nuestra historia" en Radio María. Es Director del CEPAC Universidad Católica Sedes Sapientiae.
} 


\section{INTRODUCCIÓN: SOLICITUD DE LA IGLESIA POR EL PATRIMONIO}

"El empeño de quien construye y decora la casa del Señor recibe su estatuto de la Sagrada Escritura". Mons. Mauro Piacenza, presidente de la Comisión de Bienes Culturales del Vaticano, en su Mensaje a los participantes en la XVIII Cátedra de Arte Sacro de la Universidad de Monterrey (9 de febrero de 2007) nos recordaba un texto bíblico realmente hermoso, tomado de Ex 35, 30-33: "Dando inicio a los trabajos para la Tienda del Encuentro, Moisés les dijo a los israelitas: «Mirad, Yahveh ha designado a Besalel, hijo de Urí, (...) y le ha llenado del espíritu de Dios, confiriéndole habilidad, pericia y experiencia en toda clase de trabajos, para concebir y realizar proyectos en oro, plata y bronce, para labrar piedras de engaste, tallar la madera y ejecutar cualquier otra labor de artesanía; a él y a Oholiab (...) les ha llenado de habilidad para toda clase de labores en talla y bordado, en recamado de púrpura violeta y escarlata, de carmesí y lino fino, $y$ en labores de tejidos. Son capaces de ejecutar toda clase de trabajos y de idear proyectos» ${ }^{1}$.

Los principales documentos producidos por el Vaticano en este orden son los siguientes:

1.- Carta circular a los Ordinarios diocesanos sobre la formación de los candidatos a sacerdocio sobre los Bienes Culturales, 15 de octubre de 1992.

2.- Carta circular a los Rectores de las Universidades Católicas para el envío de la "Relación sobre las respuestas de las Universidades Católicas respecto a las actividades promovidas con relación a los bienes culturales de la Iglesia”, 31 de enero de 1992.

3.- Carta circular Los Bienes Culturales de los Institutos Religiosos, 10 de abril de 1994.

4.- Carta circular La función pastoral de los archivos eclesiásticos, 2 de febrero de 1997.
5.- Carta circular Necesidad y urgencia del inventario y catalogación de los bienes culturales de la Iglesia, 8 de diciembre de 1999.

6.- Carta circular "La función pastoral de los Museos Eclesiásticos", 15 de agosto de 2001.

7. Inventario de los bienes culturales de los Institutos de Vida Consagrada y de las Sociedades de Vida Apostólica: algunas orientaciones prácticas (15 de septiembre de 2006).

Una de las definiciones más completas se expresa en la Carta del 2001: "Los bienes culturales en cuanto expresión de la memoria histórica, permiten redescubrir el camino de la fe a través de las obras de las diversas generaciones; por su valor artístico manifiestan la capacidad creativa de los artistas, los artesanos y los oficios locales que han sabido imprimir en las cosas sensibles el propio sentido religioso y la devoción de la comunidad cristiana (...) Por su contenido cultural transmiten a la sociedad actual la historia individual y comunitaria de la sabiduría humana y cristiana (...); por su significado litúrgico, están destinados especialmente al culto divino"3.

Las sugerencias y directivas impartidas en estas ocasiones han tenido un profundo eco, han sido acogidas con entusiasmo, y han ido generado un cambio de opinión en el aprecio de la inestimable herencia patrimonial de la Iglesia, generando movimientos de opinión e iniciativas concretas de la mayor significación. Entre las más llamativas sobresale la respuesta de las universidades, que han ido incorporando a sus programas la temática propuesta por el papa; de particular importancia ha sido en este sentido la apertura en la Universidad Gregoriana de Roma, desde 1991, con notable éxito, de un "Curso Superior para los Bienes Culturales de la Iglesia"; cátedras análogas han incorporado a continuación, entre otras, las universidades de París, Lisboa, México y Brescia (Italia), sin contar con otros centros

\footnotetext{
2 http://www.vatican.va/roman_curia/pontifical_commissions/pcchc/documents/rc_com_pcchc_20070209_xviii-monterrey_ sp.html

3 http://www.vatican.va/roman_curia/pontifical_commissions/pcchc/documents/rc_com_pcchc_20010815_funzione-musei sp.html
} 
académicos en diversas partes del mundo. A juicio de Juan Pablo II, el patrimonio cultural y artístico de la Iglesia, que constituye un noventa por ciento del patrimonio mundial, es de un valor evangelizador incontestable, expuesto a la apreciación de los hombres de toda lengua, raza y nación, un testimonio único de la inspiración divina respecto al arte, el pensamiento y la $\mathrm{fe}^{4}$.

El historiador Fernando Armas ${ }^{5}$ nos recuerda que en su acepción más tradicional, el patrimonio es el "legado de nuestros padres", referido a las nociones de herencia y paternidad. Es la herencia que hemos recibido de nuestros ancestros, que viene de una época pasada, y que se constituye en un legado que asegura el recuerdo de nuestra familia No sería sino hasta el advenimiento de la Ilustración, en el siglo XVIII, que la mentalidad racional, en plena crítica a la tradición y la religión, le daría al patrimonio una dimensión semántica extensiva, incursionando en la esfera de lo público. El patrimonio era ahora una herencia pública. Y no de individuos exclusivamente, sino que sobre todo de la Nación. El Estado pasó a apropiarse del discurso patrimonial, y como bien se ha señalado el patrimonio nunca más abandonó el discurso estatal, como esencial para producir la conciencia de la Nación. Así el Estado produjo y reprodujo un discurso en torno al patrimonio de la Nación, donde se reivindicaba la existencia de un legado, material y espiritual, que podía remontarse a miles y miles de años. El patrimonio, como herencia de la nación, era parte de la memoria colectiva social.

La Iglesia, que se consideraba hasta antes del siglo XVIII, en el centro de la representación social y voz de la comunidad, tuvo que declinar su puesto preponderante ante el proceso de desacralización donde la vida colectiva no solo pasó a estar representada por el Estado, sino también por la familia, grupo o clases. Orillado el concepto de la sociedad basada en la revelación divina la conciencia crítica abría las válvulas del entendimiento de la sociedad como construcción histórica, que se concretaba mediante prácticas sociales en el espacio público tal como afirma el filósofo Habermas. Grupos y clases se definían en el espacio público, mientras el Estado participaba activamente a través de ella en la construcción de un discurso patrimonial de identidad. Pero, por ser la sociedad un producto de prácticas, a la larga no solo la modernidad permitió que la Iglesia (Católica en nuestro caso) ensayara formas de penetración y presencia en tal espacio.

Pero después de una etapa de optimismo, es público y notorio en torno al Concilio Vaticano II (1962-65) el problema de las adaptaciones inadecuadas de las iglesias tradicionales, de las ventas clandestinas y de los robos de objetos de arte sacro, comienza un periodo de mayor toma de conciencia sobre el patrimonio cultural por parte del Estado y de la Iglesia. La sociedad va alcanzando niveles de bienestar que le permite dedicar más tiempo al disfrute cultural y mayores esfuerzos económicos para promover y conservar la cultura. Se impone la necesidad de establecer líneas de cooperación entre el Estado y la Iglesia.

También toma cuerpo la tarea de conservar, restaurar y custodiar el gran legado histórico del arte religioso, precaver y evitar lamentables robos y expoliaciones del tesoro artístico, y la necesidad de una más estrecha colaboración entre la Iglesia y el Estado. En 1974, se proponían tres soluciones: catalogación, restauración y uso adecuado. Al inicio de la década de los 80, en varios países especialmente de Europa quedaron delineados los grandes temas del patrimonio cultural de la Iglesia, hasta el punto de quedar patente la necesidad de una Comisión Episcopal que tratara específicamente del patrimonio cultural de la Iglesia, que, en relación con la sociedad civil, ya había rebasado con mucho el campo interno de lo estrictamente litúrgico o de lo administrativo eclesiástico, para convertirse en un bien de interés social. Se había pasado del concepto de ures sacra et pretiosa» al de «bien cultural» ${ }^{6}$. La necesidad

\footnotetext{
4 Gabriel Guarda: http://humanitas.cl/html/biblioteca/articulos/d0431.html

5 Entre libros y estudios, citamos: Fernando Armas Asín La invención del patrimonio católico (Modernidad e identidad en el espacio religioso peruano (1820-1950) Asamblea Nacional de Rectores, Lima 2006, 183 pp.

6 El paso se comprende mejor al considerar el caso de los archivos eclesiásticos, que, de ser meros depósitos de títulos de derechos o de trámites administrativos, han pasado a ser lugar de consulta para dar a conocer la memoria de la Iglesia y la
} 
de tener un interlocutor válido ante el Estado, en materia cultural, y de atender la dinámica propia de los bienes artísticos e históricos de la Iglesia, llevó a las Conferencias Episcopales Española a crear una Comisión específica para el patrimonio cultural.

Dentro de esta rica trayectoria eclesial de preocuparse por los bienes, ocupa un puesto preferencial el segundo arzobispo de Lima y patrono de todos los obispos de América Santo Toribio Alfonso Mogrovejo7. Mi comunicación trata de presentar su interés por los bienes culturales de la iglesia y sociedad de su tiempo.

\section{La forja de la identidad del Perú}

Justo dos años antes de finalizar el siglo XVI, en 1598, a los 18 años de hacerse cargo de la iglesia de Lima, Mogrovejo envía una "relación y memorial" al Papa en el que da cumplida información de su labor, así como un retrato fidedigno de su dilatada arquidiócesis con cinco "villas" (Ica, Cañete, Chancay, Santa y Saña) y cuatro "ciudades" (Trujillo, Huánuco, Chachapoyas y Moyobamba). De los 30 densos apartados, seleccionamos el primero: "Después que vine a este Arzobispado de los Reyes de España, por el año de ochenta y uno, he visitado por mi propia persona (...), muchas $y$ diversas veces, el distrito, conociendo $y$ apacentando mis ovejas, corrigiendo $y$ remediando, lo que ha parecido convenir, $y$ predicando los domingos y fiestas a los indios y españoles, a cada uno en su lengua, y confirmando mucho número de gente, que han sido más de seiscientas mil ánimas (...)y andado y caminando más de cinco mil doscientas leguas, muchas veces a pie, por caminos muy fragosos y ríos, rompiendo por todas las dificultades y careciendo algunas veces yo y la familia, de cama y comida, entrando a partes remotas (...) adonde ningún Prelado ni visitador había entrado"8.

En la construcción de la identidad del Perú, será decisivo el Tercer Concilio Limense. El 19 de abril de 1583 santo Toribio, a costa de su propia humillación, reabría el concilio venciendo la animadversión reinante y haciendo caso omiso de la intemperancia del prelado de Cuzco, Lartaún, el cual se permitió afirmar ante el legado real que "el arzobispo no era cabeza ni presidente del concilio, sino el Espíritu Santo". Con motivo de tales incidentes exclamará: "No temo ni tiemblo a cosa alguna. Lo que más me ase vivir con inquietud no es lo que padezco, sino el temor de que mis ovejas, escandalizadas de estas varias revoluciones, caigan en culpas y ofensas de Dios...La consideración de que los trabajos que he padecido vienen derechamente de mano de Dios, jamás me ha puesto triste; antes, con ese convencimiento, he vivido alegre, en medio de ellos, las busco con contento". Y así, pese a las tensiones, logró convencer a los padres conciliares para que se prescindiese de la causa judicial del de Cuzco y en cambio se ofreciese al pueblo cristiano los anhelados decretos de reforma.

Gracias a su tesón y ecuanimidad, su celo y santidad, salió adelante el Concilio, instrumento privilegiado de la reforma tridentina en América en un ambiente de absoluta concordia $y$ unanimidad entre los asistentes. Sus normas regirán la «nueva cristiandad de las Indias» -como gustaba repetir- hasta el Concilio Latinoamericano de 1899. Será el estatuto de la Iglesia americana (cuatro arzobispados y 17 obispados) para tres siglos. El concilio será decisivo para configurar un solo Perú, como se comprueba por sus cánones, en

memoria de los pueblos. De res sacra a bonum culturale hay tanto como de Archivo Secreto a Archivo Histórico abierto al público. http://www.carrasco-terriza.com/publicaciones.htm

7 En la bibliografía ofrezco varios de mis trabajos sobre la personalidad y el contexto de Santo Toribio.

8 Todo esto se recogió en la exposición itinerante "Toribio Alfonso Mogrovejo: Identidad y multiculturalidad en América Latina" que causó un fuerte impacto en Rímini (Italia) en el Meeting por la amistad de los pueblos de agosto del 2006 y en Lima en el Instituto Riva Agüero, Casa Osambela, el mismo año y en la Sala Mamacha del Museo Nacional de Pueblo Libre desde el 19 de abril al 28 de mayo del 2007. La muestra fue promovido por el Movimiento "Comunión y Liberación" y elaborada por un grupo de docentes de la Universidad Católica "Sedes Sapientiae" de Los Olivos y se compone de 21 paneles; trata de dar a conocer la vida del santo antes de su llegada a América, la relación de España con el mundo y con América en aquellos tiempos, así aspectos históricos, artísticos, culturales y geográficos del Perú. Además, se busca enfatizar la tarea de valorización que hizo de las culturas locales, principalmente a través del estudio de las lenguas, su escritura, difusión, y la publicación del catecismo, primer libro impreso en América del Sur y que se hizo simultáneamente en tres idiomas: castellano, quechua y aymará 
los que desaparece la dicotomía de temas y constituciones entre indios y españoles. Se puede decir que, a partir de este momento, la Iglesia va forjando un solo pero diverso Perú en el que se articulan españoles y criollos, los mestizos, sin perder su importancia los indígenas que son el sustrato básico de la nueva Patria que nace. Frutos suyos serán la fundación de Seminarios (calcados del Colegio Mayor de Oviedo de Salamanca, la organización de las visitas canónicas para comprobar que todo se aplicaba, la publicación de un "Catecismo" en los tres idiomas (castellano, quechua y aymará), el "Sermonario" (guía de párrocos y predicadores), "Confesonario" (manual de instrucciones para los penitentes).

\section{Edificó y reparó iglesias}

Tal es el sentir y el testimonio de varios de los declarantes en el proceso de beatificación. Así el $\mathrm{P}$. Juan de Figueroa, OP, natural de Arequipa, hijo de García de Figueroa y de Isabel Martín, 81 años, provincial de Guamanga y de Arequipa, visitador general de las provincias de Parinacocha y Condesuyos del Cuzco, también de los conventos y doctrinas de la ciudad de Arequipa, declara el 5 de mayo de 1659: "Y que procuró que la iglesia nueva de los indios se fundase con toda firmeza conforme a la verdadera y santa iglesia romana y asimismo que recibía con notable agrado a los hijuelos pequeños de los indios y les enseñaba la doctrina cristiana y a muchos infieles que estaban en las tinieblas de sus errores les descubrió la luz del Evangelio y a los adultos rudos se le enseñó y a los inclinados a vicios los apartó de ellos con su ejemplo y predicación aumentando siempre a los pecadores a que se arrepintiesen, que dio consejo a los ignorantes, que visitó de día y de no he sin hacer excepción algún de personas, aunque fuesen viles y a los enfermos y les hizo socorros espirituales y temporales, que edificó y reparó iglesias"

Por su parte el Capitán Basilio de Vargas, de Sevilla, 77 años, 14 de mayo de 1659, quien
"Le conoce y le habla una vez en el convento de monjas de Santa Clara antes de entrar las religiosas en él con ocasión de ir con la mercader mujer de Luis de Pernia. Iban a ver el edificio del dicho convento que se estaba acabando "y hallaron en el claustro más principal al dicho siervo de Dios Don Toribio que les dio licencia para que entrasen a ver la obra del dicho convento y que esto sería por el año de 1604 'poco más o menos y que el dicho siervo de Dios estaba solo con los obreros y oficiales que hacían la dicha obra. y que valdrá hoy su caudal efectivamente poco más de 2000 pesos en dos negras y dos negritos pequeños y otras alhajas, y que demás de esto le deberán en dietas poco ciertas hasta cantidad de 17.000 pesos poco más o menos" (Ibídem).

Un singular testimonio nos lo ofrece el más que centenario labrador Gaspar Lorenzo de Rojas, natural de La Paz, 115 años, casado, quien le conoció en la visita a Yauyos, Jauja, Tarma, Chincacocha, Ica, Nasca. En Lunaguaná, asiento de Cataquasi, "donde el dicho siervo de Dios halló muchos indios desparramados y en sus rancherías, sin población ni iglesia y considerando que la parroquia donde estaban asignados distaba de aquel paraje cinco leguas de asperísima sierra, por lo cual mandó reducir los indios y fabricó con toda presteza un iglesia parroquial a su propia costa y este declarante vio abrir los cimientos y en una procesión llevar al dicho siervo de Dios en sus propias manos consagrada la piedra que se había de asentar primero, la cual vio poner en el cimiento al dicho siervo de Dios, a un lado del altar mayor, echándole su bendición arzobispal y poniendo debajo de ella alguna moneda como fue un patacón diciendo que había de ser una barra" (Ibídem).

El Padre. Diego de Trevejo, OFM, de Lima, hace un recuento de sus obras al atestiguar que "junto al dicho monasterio fundó también el recogimiento de las mujeres mal casadas y últimamente sabe que edificó a su costa la capilla de Nuestra Señora de Copacabana

\footnotetext{
Todos estos testimonios se guardan en el Archivo Arzobispal de Lima. "Proceso de canonización de Santo Toribio". Primero cuaderno original de las informaciones que por autoridad apostólica han hecho en la Ciudad de los Reyes Jueces el Ilmo. y Rvdo. Sr. Dr. D. Pedro de Villagómez, arzobispo de dicha ciudad y las dignidades y 4 canónigos más antiguos de esta dicha ciudad, notario actuario el Br. Pedro del Arco y diputado el Br. Bernardo de Zela despacháronse los trasuntos de estas informaciones a 25 de noviembre del año de 1660.
} 
donde le veía hacer órdenes y confirmaciones muchas veces y que a este testigo confirmó en la dicha capilla" (Ibídem).

Como compendio de su obra constructora es elocuente el artículo 34 del Sumario y memorial ordenado por D. Pedro e Villagómez, arzobispo de los Reyes y en la Causa de la Beatificación y Canonización del Siervo de Dios el Ilustrísimo Señor Don Toribio Alfonso Mogrovejo, arzobispo que fue de esta ciudad: "Que emprendió muchísimas y verdaderamente difíciles cosas por Dios y por la esperanza de la bienaventuranza eterna, pues con manifiestos peligros de la vida hizo largas peregrinaciones en las muchas visitas de su diócesis, entrando a naciones bárbaras de indios, hasta entonces casi no conocidas, solamente con el deseo y cuidado que tenía de extender la gloria de Dios, en tanto grado, que muchas veces quedó solo entre aquellos desiertos, selvas y bosques, y entre las tinieblas oscurísimas de la noche, y algunas veces en los más altos despeñaderos de los montes estuvo cerca de despeñarse, pero más veces fue arrebatado de la velocidad de las aguas pasando los ríos, pero salió salvo no sin auxilio de Dios, que había mandado a sus ángeles, que guardasen a su siervo en todos los caminos y un tal vez fue hallado helado de frío y casi sin aliento entre las lluvias y nieve y puso en perfección otras muchas cosas dificultosas pues edificó de nuevo desde sus fundamentos y reedificó y reparó y enriqueció muchas iglesias y lugares píos, en los cuales puso mucho trabajo $y$ gastó y le costó muchas adversidades y halló contradicciones y contiendas" 10 .

Un detalle de la delicada conciencia de su respeto por las "huellas" del pasado como la tradición de la predicación del apóstol Santo Tomás y las huellas veneradas en una roca para lo que ordenó hacer una capilla: Antonio de la Calancha OSA, definidor dos veces, $y$ rector del colegio de san Ildefonso de Lima, prior del convento, de Trujillo, y de esta dicha ciudad, "El Santo Arzobispo de los Reyes DTAM, en cuya diócesis caía entonces la provincia de Chachapoyas hizo cuando fue a visitar con gran acuerdo y prudente cuidado averiguación de la verdad, ocasionado de la voz común y de la gran devoción que con la peña y huellas tenía toda la comarca"11: Lo confirma uno de los declarantes: "Averiguado por el santo Arzobispo aprobó la devoción de los fieles porque también averiguó mercedes que Dios hace por las huellas y autorizó el respecto yendo él y besando las pisadas y cóncavos de el bordón y rodillas y tras él todos sus clérigos y demás gentío hizo hacer una capilla donde quedase la losa"12.

\section{Constructor de La Catedral}

La primitiva catedral de adobe sucedió al templo edificado por Pizarro y la comenzó el arzobispo Loaysa hacia 1550 . Se terminó en 1551, medía 260 pies, era toda ella de adobe, excepto la capilla mayor que era de piedra abovedada y fue costeada por doña Francisca Pizarro, hija del conquistador. El citado Arzobispo emprendió la obra de la segunda catedral, dándole mayor extensión y orientándola de este a occidente y no de norte a sur como la anterior. En 1589 Mogrovejo escribía al Rey diciéndole que "no se ha puesto piedra en ella y los cimientos de media iglesia...están a medio estado de mucho tiempo a esta parte". En 1593 -tal como señala el Prelado en otra carta- Cañete mandó suspender la obra alegando que la Real Cédula en que se ordenaba la repartición prevista para su construcción estaba desfasada. En 1597 el Cabildo -en carta al Rey- informa que las obras se habían detenido, reclamando ayuda para su término.

En 1602, el Rey envió a Real Audiencia de Lima una cédula reclamando información

\footnotetext{
10 Sumario y memorial ajustado de las probanzas que por deposiciones de testigos e instrumentos se han hecho por el ISD D. Pedro e Villagómez, arzobispo de los Reye y demás Señores Jueces Apostólicos en la Causa de la Beatificación y Canonización del Siervo de Dios el IS Don Toribio Alfonso Mogrovejo, arzobispo que fue de esta ciudad. En Lima, en la Imprenta de Juan de Quevedo y Zárate. Año de 1662.135 pp. Biblioteca Nacional de Lima.

11 Crónica moralizada del Orden de San Agustín Libro 2, c.3, n.8, f.328: impreso en Barcelona 1638 f. 329, columna primera.

12 Archivo Arzobispal de Lima. Proceso de canonización de Santo Toribio. Quinto cuaderno original, de testimonios y otros instrumentos hechos en la causa de la Beatificación y Canonización del Venerable Siervo de Dios D. Toribio Alfonso Mogrovejo, Arzobispo que fue de la Santa Iglesia Metropolitana de la Ciudad de Los Reyes, actuados en Lima por los años de 1661,1663 y 1664
} 
acerca de la suma gastada y lo que se precisaba. Los oidores, de acuerdo con el repartimiento practicado, aplicaron 16.000 pesos anuales a la fábrica catedralicia, de los cuales 6.000 corresponderían al Rey. Por esas fechas Santo Toribio manifiesta su sorpresa al Monarca de que le hubiesen dicho que la obra se había detenido cuando ya se habían cubierto las bóvedas laterales. Sin embargo, solo en 1625 se pudo inaugurar el nuevo templo.

No puede achacarse desidia ni mucho menos al Arzobispo. Pues aunque parase en la visita, fuera de Lima, la mayor parte del tiempo, lo que se necesitaba era plata y ésta correspondía gestionarla a los virreyes. Éstos -salvo D. Luis de Velasco- la dejaron a un lado. En su honor hay que ponderar que el 2 de febrero de 1601 pudo celebrarse su dedicación, aunque faltase la mitad (portadas y torres), la primera parte de la tercera catedral. Fue Mogrovejo muy celoso del decoro de la Catedral como lo demuestran sus desvelos por mejorar su fábrica y las visitas de inventario realizadas. Nos lo demuestra un documento forrado en pergamino, mandado comprar por el santo, $y$ que se titula "Inventarios de esta Santa Iglesia de 1604 hasta 1852"13.

\section{Templos y parroquias}

El arzobispado de Lima abarcaba todo el virreinato excepto Cuzco y Arequipa. Estaba dividido en partidos, corregimientos en lo político y éstos en curatos. En el Corregimiento de Lima estaban las parroquias de San Sebastián, Santa Ana, San Marcelo, San Lázaro y el pueblo de Santiago del Cercado. Alrededor de Lima estaban los curatos de Late, Surco, Lurín y Pachacámac, Lurigancho, Magdalena, Carabayllo. La excelente obra del Dr. J.A. del Busto San Martín de Porras (Lima 1992) recuenta las iglesias y templos de Lima: Sagrario (1535), junto a la Catedral; San Sebastián (1554), Santa Ana (1570), Santiago del Cercado (1571), San Marcelo (1573, parroquia en 1584) Nuestra Señora de Atocha (1614), San Lázaro (1626). Templos de las órdenes: Nuestra Señora del Rosario, Nuestra Señora de las Mercedes, Santísimo Nombre de Jesús y san Agustín. Todos, a extramuros, tenían sus recolecciones: Santa María Magdalena, Nuestra Señora de Belén, Nuestra Señora de los ángeles y Nuestra Señora de Guía. Monasterios de monjas: Encarnación, en 1561, de agustinas; Concepción, 1573 de Clarisas; la Trinidad, 1584 (Bernardas), Descalzas de San José, 1602, Santa Clara, 1604, de franciscanas; Santa Catalina, 1622, de dominicas. Ermitas marianas: Nuestra Señora de Montserrat, Guadalupe, del Prado (1600), del Socorro (1615), Copacabana (1617), de la Cabeza (1617)

En tiempos del Prelado, se erigieron dos parroquias. La primera, San Lázaro, en el barrio del Rímac, habitado fundamentalmente por indios. Allá existía desde 1563 un hospital o Ladrería de San Lázaro, fundado por el espadero Antón Sánchez salas para cuidar, alimentar y proteger a los leprosos. Junto al hospital se levantó una capilla que sirvió a los fieles del barrio. En 1601 se erige como viceparroquia de la Catedral y se nombra como vicepárroco a uno de los sacerdotes que atendía la Catedral, poniéndole como condición que residiese en el barrio. En 1739 fue elevada al rango de parroquia. La otra parroquia fue la de San Marcelo que, aunque existía como capilla desde el obispado de Loayza, fue erigida como parroquia en 1584, siendo su primer párroco el P. Juan Lázaro Najarro. El pobre templo de los primeros años fue enriquecido al ser habitado el barrio por gente pudiente, de tal modo que en 1599 era ya una de las mejores parroquias. Constaba de tres naves, presidiéndolas un excelente retablo dedicado a la Virgen de los Remedios. En tiempos de la República, debido a la regulación del tráfico del centro de la ciudad, se tuvo que seccionar el templo en una de sus naves.

\section{Hospital de San Pedro}

El siempre bien informado Bernabé de Cobo, S.I. en su Historia de la fundación de Lima titula

13 Archivo del Cabildo Catedralicio de Lima. Véase: García Irigoyen, C. Santo Toribio Lima 1904 (4 tomos). San Cristóbal, Antonio "La catedral de Lima en tiempo de Santo Toribio", Revista Peruana de Historia Eclesiástica 9 , Cuzco, pp. 161-167. 
su Capítulo Primero: "De la mucha piedad y religión de esta república", y parece encontrarla fundamentalmente en la beneficencia:

No resplandece ni campea menos la piedad y misericordia con los prójimos, como lo testifican los muchos hospitales que hay fundados, donde con singular amor y regalo son curados los enfermos; las gruesas limosnas que se recogen para sustento de los necesitados; las memorias pías dotadas de buenas rentas, que se expenden en dar estado a doncellas pobres $y$ en remediar necesidades de gente desamparada; y lo que no es de menor estimación, el buen acogimiento, agasajo y comodidad que en esta república (digna por ella del honroso título de madre común) hallan todos los forasteros de cualquier nación que a ella vienen, que es tan notable, que los más ponen en olvido a sus propias patrias y se avecindan en ésta y la tienen pro propia, atraídos y pagados del amor $y$ cortesía con que son recibidos y tratados y la igualdad con que ella reparte entre sus habitadores, sin aceptación alguna de personas naturales o extranjeras, los bienes, comodidades y honras que otras repúblicas solo distribuyen y comunican a sus propios hijos y naturales, excluyendo de ellos a los advenedizos y forasteros ${ }^{14}$.

Aunque Lima disponía de siete hospitales para todos los grupos sociales, faltaban los sacerdotes. Al efecto, en 1594 se reúnen varios sacerdotes en la sacristía de la Catedral de Lima con el ánimo de fundar una cofradía, que bajo la advocación de San Pedro, para ayudar a los sacerdotes necesitados. Se redactaron las constituciones y el 29 de julio de 1595 les fue concedida la licencia de mano del Sr. Deán, Pedro Muñiz. Como Hermano Mayor resultó elegido el P. Pedro de Escobar, el bachiller Miguel Bobadilla mayordomo, Luis López de Alarcón diputado y el P. Gaspar de Montalvo, vicario de Coro. Los Hermanos serían 24, aportando 25 pesos de limosna y un cirio de
5 libras al inscribirse; anualmente, dos pesos. El resto de los sacerdotes miembros deben abonar 12 pesos y un cirio de a libra al ingresar y dos pesos al año. La fiesta principal sería el 18 de enero, cátedra de San Pedro en Roma. En un primer momento se reúnen en la misma Catedral, pero más adelante contarán con un local propio con iglesia - desde 1607- llamada San Pedro u Hospital de San Pedro.

Debido a la generosidad de los sacerdotes Gabriel Solano y el canónigo León, pudieron adquirir una casa donde se atendía a los sacerdotes enfermos desde 1598. El edificio constaba de dos patios, uno para los enfermos y el otro para los convalecientes y forasteros. El centro, que contó con el apoyo decidido del Santo, se convirtió en institución floreciente. Sin embargo, en 1671 se concedió su dirección a los Padres del Oratorio de San Felipe Neri. Con la expulsión de los Jesuitas, los Oratorianos se responsabilizaron de la iglesia y colegio de San Pablo (la actual San Pedro), trasladando a uno de sus patios el Hospital. El antiguo edificio fue traspasado a las Amparadas de la Purísima, convirtiéndose posteriormente en Escuela de Bellas Artes.

Cabe citar también el de 1598, por iniciativa de Luis de Ojeda (Luis Pecador) quien establece la Casa de Huérfanos y Expósitos, que contó con el apoyo del Virrey Conde de Monterrey y la Hermandad de Escribanos de la Ciudad, y que subsistió hasta que en 1919 se refundió en el Puericultorio Pérez Araníbar.

Baste citar, por último, el Hospital Santo Refugio de los Incurables, en la actualidad Instituto Nacional de Ciencias Neurológicas. Creado en 1669 bajo el patrocinio del prelado Toribio de Mogrovejo y con el auspicio de fray José de Figueroa, OSA, don Antonio Dávila, sacerdote, donante inicial de la casa y huerta donde se produjo uno de los milagros que decidieron la canonización del Santo; además, don Domingo de Cueto, comerciante y hombre de negocios, quien dio su fortuna; en 1698 lo regentan los Betlemitas ${ }^{15}$.

\footnotetext{
${ }_{14}$ Cobo, Bernabé Historia de la fundación de Lima Libro segundo. Capítulo Primero: "De la mucha piedad y religión de esta república" http://fondosdigitales.us.es/fondos/libros/2407/19/fundacion-de-lima/

15 Miguel Rabí Chara en El hospital refugio de incurables "Santo Toribio de Mogrovejo" de Lima. Evolución histórica. 1669 a 1997 (Lima 1997) hace un sucinto recuento de los hospitales del tiempo que estudiamos.
} 


\section{Fundador de Santa Clara}

Las estrechas relaciones entre santo Toribio y el Monasterio de Santa Clara se debieron entre otras razones a ser el prelado el más decidido valedor de lafundación, que se concretó en 1605. Fue decisivo el apoyo del portugués Francisco Saldaña quien donó 14.000 pesos para la obra. El 11 de agosto -fiesta de Santa Clarade 1605 entraban las fundadoras, religiosas de la Encarnación (Justina de Guevara, abadesa, Ana de Illescas, Bárbola de la Vega e Isabel de la Fuente) a quienes se unieron doce jóvenes más. Bien pronto, le siguieron numerosas jóvenes, como una sobrina del arzobispo, Beatriz, hija de Luis de Quiñones y Grimanesa Mogrovejo, que ingresó a los pocos meses, en 1606. Tanto en Salamanca como en Valladolid (parroquia de san Martín) se encontró el Santo con la devoción a la Virgen de la Peña de Francia. Parece ser que santo Toribio llevó esta advocación a Lima y fomentó su culto entre el pueblo. Así lo manifiesta en la carta escrita al Papa Clemente VIII, con motivo de su visita ad Limina de 1598: "Está en este monasterio una imagen de la Virgen de la Peña de Francia, de mucha devoción para el pueblo, adonde acude mucho número de gente y clérigos a decir muchas misas" ${ }^{16}$.

Como testimonio de su cordial afecto donó su corazón que aun hoy guardan como preciada reliquia. Envuelto en un blanco lino $y$ amorosamente guardado en una pequeña y sencilla custodia de bronce bañado en oro, desde cuando cesó de latir hace 400 años, el corazón de Santo Toribio de Mogrovejo sigue presente entre nosotros, en la iglesia del Convento limeño de Santa Clara, fundado por él en Barrios Altos, a pocas cuadras de la Catedral que lo tuvo como segundo Arzobispo de Lima. Este corazón, que probó los esfuerzos del andar por los caminos de la Cordillera, subiendo hasta más de 4500 metros sobre el nivel del mar y bajando luego al fondo de valles y quebradas sobrecogedoras, para volver inmediatamente a alcanzar grandes alturas, $y$ así por leguas y leguas, año tras año, y que antes de la aventura andina acompañó ardoroso al incansable misionero por los arenales del desierto costero, ha dejado de latir. Pero ha sido escogido por Dios para que permaneciera aquí, a nuestro lado, como la más preciosa reliquia de su gran apóstol, símbolo del indefectible amor con el que sigue a cada uno de nosotros desde la Casa del Padre.

El sucesor en la silla arzobispal, colegial también de San Salvador de Oviedo en Salamanca, natural de Castroverde de Campos (Zamora) y sobrino del santo, Pedro Villagómez, tuvo la suerte de tramitar la beatificación, para la que escribió una "Vida de Santo Toribio" en verso heroico. En el Convento de Santa Clara de Lima, donde se conserva su corazón, figuran estas sentidas palabras de su sobrino y sucesor en la silla arzobispal: Al Corazón del Ilustrísimo y Revdo. Sr. Toribio Alfonso Mogrovejo que debe ser adscrito por sus méritos entre los dioses, sepultado en Lima en convento de Santa Clara. Toribio mandó que su propio corazón fuese entregado a esta urna hasta que (como un espíritu) alcance los astros.

El Sumario formado por el mismo Villagómez, dedica el número 74 a destacar que el Santo edificó "templos y lugares píos":

Del "Memorial del Convento de Santa Clara" n.42, f.1 "En este año de 1605, venimos a fundar este convento de Santa Clara por mandado del Il.Sr. Arzobispo de esta Ciudad de los Reyes y fundador de esta casa y coadjutor Francisco de Saldaña, siendo abades de nuestro Convento de Nuestra Señora de la Encarnación, la ilustre Señora doña Mencía de Sosa, fundadora de su mis casa y con su bendición y beneplácito $y$ con licencia del Sr. Doctor Miguel de Salinas, Provisor y Vicario general de este arzobispado, por tener particular comisión para esto del Ilmo. Arzobispo Don Toribio Alfonso Mogrovejo, nuestro fundador y Su Señoría la tenía de la Sede Apostólica de la Santidad de Clemente Octavo, como se verá en sus propios originales ${ }^{17}$.

\footnotetext{
16 "La Iglesia de Lima en el año 1598" Toribio Alfonso Mogrovejo: Identidad y multiculturalidad en América Latina" Comunión y Liberación, Lima 2006 p. 56

17 Sumario y memorial ajustado de las probanzas que por deposiciones de testigos e instrumentos se han hecho por el ISD D. Pedro e Villagómez, arzobispo de los Reye y demás Señores Jueces Apostólicos en la Causa de la Beatificación y
} 
El 4 de enero del 2006 las actuales Clarisas pudieron celebrar el 400 aniversario de su fundación, constatando cómo aún hoy se profesa un gran afecto al jardín de este claustro virreinal y el pozo de la huerta en los que la tradición popular ubica el encuentro de los jóvenes y santos, la criolla Rosa de Lima y el mulato Martín de Porres.

\section{Copacabana}

En su defensa de las poblaciones nativas, Santo Toribio llamaba "sudor de los indios" las graves y constantes injusticias que se cometían contra ellas con motivo del tributo que debían pagar. Y esta imagen del sudor, que expresa el esfuerzo y el sufrimiento que agobiaba a estos pobladores inermes, se presenta con una fuerza extraordinaria en ocasión de un acontecimiento particularmente doloroso para muchos indios, que en 1590 habían sido obligados a viva fuerza a trasladarse del barrio de San Lázaro al barrio del Cercado, en la Ciudad de los Reyes, tal como se conocía a Lima en aquel entonces. La mañana del 28 de diciembre de 1591, la ermita donde la imagen de Nuestra Señora de Copacabana, esculpida en madera de cedro de Nicaragua por Diego Rodríguez, había sido cobijada luego de su traslado al Cercado desde San Lázaro junto con los indios, amaneció destechada y demolida en parte por orden del virrey Don García Hurtado de Mendoza, furioso por haberse el arzobispo Santo Toribio puesto del lado de los indios. Mientras se celebraba la Santa Misa, antes de trasladar la imagen de Nuestra Señora a la Catedral, los rostros de la Virgen y del Niño Jesús que ella llevaba en sus brazos empezaron a destilar abundantes gotas de sudor.

Presenciaron el prodigio y lo testimoniaron luego en la información jurídica del caso que fue encargada a don Antonio Valcázar, el sacerdote celebrante, Simón Váez, el clérigo Juan de Pineda, el pintor Melchor de Sanabria, el labrador Gaspar de Agüero, el seglar Alonso Gómez de Castro, el padre maestro Alonso Huerta, cura de la ermita, el padre jesuita Juan de Aguilar, y muchos otros testigos más.
La imagen, obra de Diego de Rodríguez en madera de cedro de Nicaragua, fue trasladada a la catedral, colocándola en la capilla ubicada junto a la puerta del perdón. Se formó una cofradía para alentar su devoción y el propio Arzobispo costeó el retablo. Aquí estuvo hasta 1606 de donde, por las obras de la nueva catedral, pasó al altar mayor y de donde se llevó en 1633 al barrio de san Lázaro, donde sigue hasta la actualidad. Podría decirse que la Virgen y el Niño se habían solidarizado con el "sudor de los indios", a quienes el santo Arzobispo había tomado bajo su protección. Varios testigos como Alonso Niño de las Cuentas, nos declaran en el proceso de beatificación de 1651 haber visto "al dicho siervo de Dios predicando de ordinario... en la capilla de Nuestra Señora de Copacabana".

\section{Asociaciones}

Conviene insistir en la repercusión social de la fe en el ordinario ambiente laboral ya que es la fuente principal de la actividad del seglar. Las cofradías tienen cuatro características fundamentales: La liturgia y la vida de oración, la caridad atenta a los más pobres y necesitados, la "cultura de vivir juntos la fraternidad cristiana", y el aporte de obras de valor artístico e histórico que mantienen viva la religiosidad popular.

La Cofradía de San José, del gremio de carpinteros, fundada en Lima en 1560, contaba con capilla propia. Los gremios de carpinteros, albañiles y canteros indios y morenos se agrupaban en otras cofradías como la de San Juan Bautista de los Pardos en la iglesia de Santa Ana, la de Nuestra Señora de los Reyes en San Francisco o San Miguel en el Cercado. En 1630 había 57 cofradías en Lima. Proliferaron en tal cantidad que el C3L de 1583 declara que "en cuanto sea posible se reduzcan a menor número y no den licencia para ordenarse otras de nuevo sin causa de mucha importancia" (III, 44). Particular actividad desarrollan las de indígenas. Sus miembros daban de comer a los pobres, visitaban a los enfermos, celebran misa, tenían

Canonización del Siervo de Dios el IS Don Toribio Alfonso Mogrovejo, arzobispo que fue de esta ciudad. En Lima, en la Imprenta de Juan de Quevedo y Zárate. Año de 1662.135 pp. Biblioteca Nacional de Lima. 
instrucción religiosa diaria y pláticas espirituales regularmente; los sábados se dedicaban a la Virgen y las comuniones eran en todas ellas frecuentes. Fueron impulsadas especialmente por los Jesuitas.

A santo Toribio le tocó confirmar la cofradía del Santísimo Sacramento en 1589. Fue gran impulsor de la Cofradía de las Ánimas; en los pueblos que visitaba fundó siempre cofradías en sufragio de ellas, alentándoles a que las sustentasen con limosnas. Era muy severo en exigir que se aplicaran debidamente las limosnas que se recaudaban para las ánimas $y$ que se cumpliesen las fundaciones y obras pías. En llegando a un pueblo, al punto tomaba cuenta al Cura párroco. Así, en la visita de 1593 lo hizo acompañado de Marcos Cano, mayordomo, acompañado del Contador nombrado al efecto Juan de Lumbreras. La de san José parece que fue fundada por el Santo, a ruego de don Hernando Moreno. La cofradía de San Crispín y Crispiano cuenta con constituciones redactadas por Francisco Cabello de Vargas, Mayordomo y Alcalde del oficio de los zapateros y Blas de Morales, su compañero, veedor del dicho oficio en 1599.

Todas estas cofradías tienen en las iglesias y conventos, sus capillas y altares bien adornados de retablos, relicarios, vasos de plata $y$ ornamentos, muchas indulgencias, jubileos y capellanías; andas costosas, ricas imágenes, sus pendones de seda, cruces y cetros de plata.

\section{Conclusión: Repara mi iglesia}

El "último gran" terremoto del 15 de agosto del 2007 golpeó a muchos de los templos tocados por la mano santa de estos primeros evangelizadores, santos como nuestro Padre de América, Toribio Mogrovejo. Es el caso de Coayllo, Cañete, que se derrumbó totalmente, o el de Huáñec, donde se celebró uno de los sínodos del Santo, y que ha sido seriamente dañado. Escribió el Papa actual en su primera encíclica "Dios es amor" que los santos son los revolucionarios de la historia que han dado al mundo luz y amor. Cuando allá por el mes de diciembre del 1205 el más alegre de los santos o el más santo de los hombres felices de la historia, Francisco de Asís salió a dar un paseo y entró a rezar en la vieja iglesia de San Damián, fuera de Asís. Y, mientras rezaba delante del Crucifijo puesto sobre el altar, tuvo una visión de Cristo crucificado que le traspasó el corazón, hasta el punto de que ya no podía traer a la memoria la pasión del Señor sin que se le saltaran las lágrimas. Y sintió que el Señor le decía: "Francisco, repara mi iglesia; ¿no ves que se hunde?". El Señor se refería a la Iglesia de los creyentes, amenazada, como siempre, por mil peligros, mas él entendió que se refería a San Damián y, como era rico, pensó que era cuestión de dinero. Se fue a la tienda de su padre, cargó el caballo con las mejores telas $y$ se fue a venderlas al mercado de Foliño. Al regreso entregó el dinero a messer Pedro, el cura de San Damián, más este no quiso aceptar, temiendo que fuese una burla, y por miedo a sus padres. Entonces Francisco decidió quedarse allí, y reparar él personalmente la iglesia y ayudar a los pobres, según sus planes.

Ojalá las numerosas iniciativas de ICOMOS, Patrimonio Vivo, Patrimonio Perú y tantas organizaciones comprometidas con el patrimonio signifiquen para todos nosotros un aldabonazo a la conciencia $y$, unidos, REPAREMOS el PATRIMONIO que se nos HUNDE. 


\section{REFERENCIAS}

Benito Rodríguez, J. A. (1990). "La promoción humana y social del indio en los concilios y sínodos americanos" Revista De Estudios Histórico-jurídicos Ediciones Universitarias de Valparaíso (Chile), pp. 299-328.

Benito Rodríguez, J. A. (1990. 1991). "La promoción humana y social del indio en los concilios y sínodos de Santo Toribio" Actas del IV Congreso Nacional de Americanistas "Castilla en América" (Caja España, Valladolid, t. III, pp. 279-294.

Benito Rodríguez, J. A. (1994). "Los derechos humanos de los indios en los concilios y sínodos americanos. 1551-1622". Derechos Humanos en América: Una perspectiva de 5 siglos. Cortes de Castilla y León, Valladolid, pp. 220-231.

Benito Rodríguez, J. A. (1995). El castellano-leonés que abrazó todas las razas: Santo Toribio Mogrovejo. Valladolid, Junta de Castilla y León.

Benito Rodríguez, J. A. (1996). "Santo Toribio Alfonso Mogrovejo en la memoria popular" Revista del Arzobispado de Lima Abril.

Benito Rodríguez, J. A. (1997). "Santo Toribio y su grupo" Esplendor Revista de la Arquidiócesis, Lima, marzo, pp. 33-40.

Benito Rodríguez, J. A. (2000). "Santo Toribio: Pionero de la educación" Revista pedagógica Maestros Lima, n.13, pp. 87-90.

Benito Rodríguez, J. A. (2000). "Alonso Huerta, el quechuista amigo de Santo Toribio" Revista Studium. Universidad Católica "Sedes Sapientiae", Lima, Año 1, No 1 pp. 81-96.

Benito Rodríguez, J. A. (2001). "Entre la Cátedra y el Altar: la Universidad y el Seminario en tiempos de Hernando de Guzmán" Revista Teológica Limense, Facultad de Teología Pontificia y Civil de Lima. Vol. XXXV, Enero-abril.

Benito Rodríguez, J. A. (2001). "La protección jurídica del indio en la legislación canónica de Santo Toribio y su paso por Trujillo (Perú)" Instituto de derecho Indiano y de Estudios Clásicos, Boletín no 1, Julio 2001, Trujillo. pp. 19-34.

Benito Rodríguez, J. A. (2001). "Archivo y Biblioteca del Seminario de Santo Toribio de Lima" Revista Peruana de Historia Eclesiástica 7, Cuzco, pp. 73-114.

Benito Rodríguez, J. A. (2001). Crisol de lazos solidarios: Toribio Alfonso Mogrovejo Universidad Católica "Sedes Sapientiae" y Ministerio de Educación y Cultura de España, Lima, 275 pp. En internet: http://www.ucss.edu.pe/toribio.htm

Benito Rodríguez, J. A. (2002). "Toribio Alfonso Mogrovejo, santo forjador del Perú (Valores destacados por sus contemporáneos". Sobre el Perú. Homenaje al Dr. José Agustín de la Puente Candamo PUCP, Fondo Editorial, Lima 2002, I, pp. 293-312.

Benito Rodríguez, J. A. (2002). "Santo Toribio y la devoción a María" Duc in altum, FTPC, Lima, pp. 11-15. 
Benito Rodríguez, J. A. (2004). "La entrada de Santo Toribio en Lima, 1581" 9-34 Revista Peruana de Historia Eclesiástica 8, Cuzco, pp. 115-154.

Benito Rodríguez, J. A. (2004). "Emilio Lissón, CM (1872-1961), destacado egresado de la UNS y arequipeño universal" Historia II Época, $N^{\circ}$ 7, Arequipa, 2004, pp. 115-126.

Benito Rodríguez, J. A. (2005). Santo Toribio Mogrovejo, según Sancho Dávila. PUCP, DRAI, Lima $42 \mathrm{pp}$.

Benito Rodríguez, J. A. (2006-a). Libro de visitas de Santo Toribio (1593-1605) (Colección Clásicos Peruanos, Pontificia Universidad Católica del Perú, Fondo Editorial 2006, pp.450+ Introdu. LVI) Introducción, transcripción y notas.

Benito Rodríguez, J. A. (2006. b) "Las visitas pastorales de Santo Toribio según su libro" Revista Peruana de Historia Eclesiástica, Cuzco, pp. 13-50.

Benito Rodríguez, J. A. (2006. c). "Hernando de Guzmán, Rector de la Universidad de San Marcos y del Seminario de Santo Toribio (1568-1638)". Uku Pacha Revista de Investigaciones Históricas Año 5. Nro. 9, Julio. 2006, pp. 71-77.

Benito Rodríguez, J. A. (2006. d). Santo Toribio Mogrovejo (1538-1606) en Quives. IV Centenario de su muerte (Lección magistral del curso 2006, UCSS) Lima, 42 pp. http://www.ucss.edu.pe/pdf/ sto_toribio\%20.pdf

Benito Rodríguez, J. A. (2006 e). Santo Toribio Alfonso de Mogrovejo, misionero y pastor en Huaraz ODEC, Huaraz.

Benito Rodríguez, J. A. (2006. f). "Toribio Mogrovejo peregrina de Salamanca a Compostela" UKU PACHA Revista de Investigaciones Históricas Año 5. Nro. 10, Diciembre 2006, pp. 5-15.

Benito Rodríguez, J. A. (2006. g) "Santo Toribio Mogrovejo, 400 años después. Respuesta incondicional a una llamada sorprendente" Revista Teológica Limense, Facultad de Teología Pontificia y Civil de Lima. Vol. XL, N 3, pp. 309-336.

Benito Rodríguez, J. A. (2007. a). "La nueva cristiandad de las Indias" o la imagen de Iglesia en tiempos de Santo Toribio Mogrovejo" (1580-1606). Revista Teológica Limense, Facultad de Teología Pontificia y Civil de Lima. Vol. XLI, N 1, pp. 65-90.

Benito Rodríguez, J. A. (2007. b). "La propuesta evangelizadora multicultural de las visitas pastorales de Santo Toribio" Toribio de Mogrovejo: Misionero, santo y pastor. Actas del Congreso Académico Internacional (Lima 24-28 de abril de 2006). Arzobispado de Lima-PUCP, Lima, 2007, pp. 114-135.

Benito Rodríguez, J. A. (2008. a). "Santo Toribio en Huacho. Documentos para estudiar su presencia" Diócesis de Huacho: Una Iglesia joven con una rica historia. 50 años de servicio pastoral. Obispado de Huacho, Huacho, pp. 27-60.

Benito Rodríguez, J. A. (2008. b) "El sacerdocio ministerial en las enseñanzas y en la vida de Santo Toribio" Actas del I Congreso Teológico Internacional De la primera evangelización a la Nueva Evangelización del Perú, celebrado en noviembre del 2006. Facultad de Teología "Redemptoris Mater", Callao, Perú, pp. 32-60. 
Benito Rodríguez, J. A. (2008.c) "Santo Toribio, siempre en camino" Compostellanum, Santiago de Compostela, Vol.LIII, Nn.3-4, julio-diciembre, pp. 431-450.

Benito Rodríguez, J. A. (2009). Santo Toribio Mogrovejo para niños Colegio y Parroquia Santiago Apóstol de Surco, Lima, 28 pp.

Benito Rodríguez, J. A. (2010). "Las primeras constituciones del seminario de Santo Toribio (1609)" Revista Teológica Limense, Facultad de Teología Pontificia y Civil de Lima. Vol. XLIV, No 2, pp. 217-252.

Benito Rodríguez, J. A. (2012). "El seminario fundado por Santo Toribio de Mogrovejo en Lima" Homenaje a José Antonio del Busto Duthurburu (Tomo II). Editorial: Fondo Editorial de la Universidad Católica del Perú (PUCP). Editores: Margarita Guerra Martiniṛre y Rafael SánchezConcha Barrios.

Benito Rodríguez, J. A. (2012) Santo Toribio, defensor y padre del indio (I) Los Primeros Años Del Gran Obispo de Lima. http://infocatolica.com/blog/historiaiglesia.php/1111131039-santo-toribiodefensor-y-padr

Benito Rodríguez, J. A. (2012). Las visitas pastorales de Santo Toribio (y II) Recorrió Miles de Kilómetros Visitando su Grey. http://infocatolica.com/blog/historiaiglesia.php/1201140146-lasvisitas-pastorales-de-san

Dammert Bellido, J.A.: Santo Toribio, modelo de celo apostólico, fortaleza y humildad. Lima, Riva Agüero.

El clero diocesano en el Perú del siglo XVI Instituto Bartolomé de las Casas-CEP, Lima, 1996.

"El indígena en el Tercer Concilio Limense" Revista Teológica Limense. Vol. XVI 3, sept.-dic. 1982.

Duran, J.D. El Catecismo del III Concilio provincial de Lima y sus complementos pastorales (158485) Estudio preliminar. Textos. Notas Buenos Aires, 1982.

Dussel, E. El episcopado latinoamericano y la liberación de los pobres (1504-1620). México 1979.

Echave Y Assu, Fco. La estrella de Lima, convertida en sol. Amberes, 1688.

Fernández García, P. Enrique Perú Cristiano. PUCP, Lima, 2000.

Glave, L.M. "Toribio de Mogrovejo, el Estado y la Nación en el Perú. Discurso de orden en el homenaje de la Universidad Nacional Mayor de San Marcos" Toribio de Mogrovejo: Misionero, santo y pastor. Actas del Congreso Académico Internacional (Lima 24-28 de abril de 2006) Arzobispado de Lima-PUCP, Lima, 2007, pp. 239-242.

García Irigoyen, C. Santo Toribio. Lima, 1904 (4 tomos).

García Irigoyen, C. Santo Toribio... Las fiestas centenarias. 2 t. Librería San Pedro, Lima, 1908.

González Fernández, Fidel: "Los santos latinoamericanos, fruto eminente de la evangelización". Historia de la evangelización de América. Pontificia Comisión para América Latina, Ciudad del Vaticano, 1992. 
Guerrero, N. Antonio El Fénix de las becas. Salamanca, 1728.

Iraburu, José María Hechos de los apóstoles de América. Cuadernos Gratis Date 5 (Perú), Pamplona, 1992.

Juan Pablo II Lecciones de Santo Toribio. A la Conferencia Episcopal de Perú Documentos Palabra, Lima, 1985.

Landazuri, Juan "Santo Toribio Legislador". Revista Teológica Limense Vol. XVI 3, sept.-dic.

León Pinelo, Antonio de Vida del Ilustrísimo y Reverendísimo D. Toribio Alfonso Mogrovejo, Arzobispo de la ciudad de los Reyes. Madrid. 1653. Lima. 1906.

Leturia, P. Santo Toribio de Mogrovejo, el más grande prelado de la América española. Roma, 1940.

Levilier, R. Santo Toribio de Mogrovejo, organizador de la Iglesia en el Virreinato del Perú, Madrid, 1920.

Lohmann Villena, G. "Santo Toribio, el Limosnero". Boletín del Instituto "Riva Agüero", Lima, 1994, 19, 1992.

"El espolio del arzobispo Alfonso Mogrovejo". Sobre el Perú. Homenaje al Dr. José Agustín de la Puente Candamo. PUCP, Fondo Editorial, Lima 2002, II, pp. 761-678.

López Trujillo, A. "Santo Toribio, precursor de la liberación cristiana en América Latina". Revista Teológica Limense Vol. XVI 3, Sept.-dic. 1982. También en Caminos de evangelización BAC, Madrid 1985, pp. 284-289.

Márquez Zorrilla, P.S. Santo Toribio de Mogrovejo, Apóstol del Perú. Huaraz, 1970.

Mogrovejo, Napoleón Santo Toribio de Mogrovejo, defensor del indio americano. Caracas, 1987.

Montalvo, F. A. de. Breve teatro de las acciones más notables de la vida del bienaventurado Toribio, Arzobispo de Lima Roma 1683 BNL, X 209.22; T 68M.

Montalvo, F. A. de. El Sol del Nuevo Mundo ideado y compuesto en las esclarecidas operaciones del bienaventurado Toribio, arçobispo de Lima... Roma 1683 BNL, X269.22; T 772 M.

Concilia limana, constitutiones synodales et alia monumenta quibus beatus Toribius archiepiscopus limanus ecclesias peruani imperii mirifice ilustravit. Roma, 1684.

Nieto Velez, Armando "La Iglesia Católica en el Perú" (C. III. La obra creadora de los arzobispos Jerónimo de Loayza y Santo Toribio de Mogrovejo). Historia del Perú, XI, Juan Mejía Baca, Lima, $1984,5^{\mathrm{a}}$ ed. pp.457-480.

“Contexto histórico del C3L” Revista Teológica Limense Vol. XVI 3, sept.-dic. 1982.

La primera evangelización en el Perú. Hechos y personajes. "Santo Toribio modelo de pastor" VE.

Pastrana Riol, Apolinar "Santo Toribio de Mogrovejo, modelo de obispo evangelizador de Iberoamérica”, Santuario, marzo-abril. Madrid, 1993. 
Pereda López, Agustín Santo Toribio de Mogrovejo, $2^{\circ}$ Arzobispo de Lima, a los 450 años de su nacimiento. Lima, 1989.

Pini, E; M. León, J. Villanueva. Santo Toribio de Mogrovejo: Apóstol del Callejón de Conchucos. Prelatura de Huari, Lima, 1995.

Puente Candamo, J. A. de la. "Santo Toribio y la formación del Perú" en Historia de la Evangelización de América Pontificia Comisión para América Latina, Ciudad del Vaticano, 1992, pp. 831-840.

Puig Tarrats, E. "La tumba de Santo Toribio en Zaña" Proyecciones: Vida universitaria -- Año 2, No. 3 (2005) pp. 8-9.

Ramírez Martín, J. "Santo Toribio de Mogrovejo". Vallisoletano t. IV, pp.197-224, Valladolid, 1984.

Redondo Cadenas, F. Santo Toribio Alfonso de Mogrovejo, natural de Villaquejida. Oviedo, 1940.

Santo Toribio de Mogrovejo y su pastoral eucarística. León, 1964.

Ripodas Ardanaz, D. El culto a Santo Toribio de Mogrovejo, un capítulo de la presencia de América en España (1679-1810), II Congreso Argentino de Americanistas 1997. Sociedad Argentina de Americanistas, Buenos Aires, 1998, pp. 289-318.

"Una comedia sobre Santo Toribio de Mogrovejo en el Madrid de Felipe V". Sobre el Perú. Homenaje al Dr. José Agustín de la Puente Candamo. PUCP, Fondo Editorial, Lima 2002, II, pp. 1029-1040.

Rocca Torres, L. Santo Toribio y el pueblo de Zaña Parroquia, 1993, Zaña.

Rodríguez Valencia, V. Santo Toribio de Mogrovejo, organizador y apóstol de Suramérica. (Madrid CSIC 1957) 2 t.

Sáenz, A. "Santo Toribio de Mogrovejo" Arquetipos cristianos Fundación Gratis Date, Pamplona, 2005, pp. 203-251.

San Cristóbal, Antonio "La catedral de Lima en tiempo de Santo Toribio", Revista Peruana de Historia Eclesiástica 9, Cuzco, pp. 161-167.

San Martín, José El Cristo del Otero y Santo Toribio Diputación Provincial, Palencia, 1985.

Sánchez Prieto, N. Santo Toribio de Mogrovejo, apóstol de los Andes BAC, Madrid, 1986.

Stehle, E. L. Testigos de la Fe en América Latina. Capítulo. "Santo Toribio" Verbo Divino Navarra 1982.

Trujillo Mena, V. La legislación eclesiástica en el Virreinato del Perú durante el S.XVI. 1963.

Vargas Alzamora, A. Santo Toribio y la Nueva Evangelización (Lima 1991).

Vargas Ugarte, R. Santo Toribio, segundo arzobispo de Lima Paulinas Lima 1989.

Velázquez, J. E. "Con las huellas de Santo Toribio Alfonso de Mogrovejo" en Diócesis de Huaraz. Cien años de vida diocesana. 15 de mayo 1899-1999. Huaraz 1999. 
Villegas, J. Fiel y evangelizador: Santo Toribio de Mogrovejo, Patrono de los obispos de América Latina. Folletos Populares, Col. "Sentir con la Iglesia" Montevideo 1984.

VIllagomez, P. de. Sumario y memorial ajustado de las provanzas que por deposiciones de testigos e instrumentos se han hecho por el Ilmo. Sr. D. Pedro de V... en la causa de beatificación y canonización del Siervo de Dios el IS Don Toribio Alfonso Mogrovejo, arzobispo que fue de esta ciudad. Lima, Imprenta de Juan de Quevedo y Zárate. Año de 1662. 